\section{Thermal analysis of steel-concrete composite cross sections via CS-ASA/FA}

\begin{abstract}
When exposed to high temperatures, such as in a fire situation, the physical and resistance characteristics of the materials employed in the structure deteriorate as the temperature increases. This fact promotes a considerable loss in the bearing capacity and stiffness of the structural system. The verification of a structure exposed to fire depends primarily and principally on the thermal analysis of the cross section of the structural element. This analysis permits determination of the temperature variation or temperature range in the element from the boundary conditions provided by the fire model adopted. As such, this study had the objective of performing a thermal analysis in a transient regime by means of a finite element method on steel-concrete composite cross sections that are employed in civil construction through use of the Computational System for Advanced Structural Analysis/Fire Analysis (CS-ASA/FA). Two cross sections are analyzed and the results obtained were satisfactory. In addition, different iterative solution processes were adopted in the analysis. Parametric studies were also performed related to the mesh variation of the finite elements and time increase. From the results, it was possible to conclude that CS-ASA/FA can supply the necessary information when a thermo-structural analysis is performed for the evaluation of strength and stiffness losses of the structural material when exposed to fire.
\end{abstract}

Keywords: thermal analysis, fire, temperature, composite cross section, FEM.
Paulo Anderson Santana Rocha

Professor

Universidade Federal de Ouro Preto - UFOP

Escola de Minas

Departamento de Engenharia Civil

Ouro Preto - Minas Gerais - Brasil

paulorocha@em.ufop.br

\section{Ricardo Azoubel da Mota Silveira}

Professor

Universidade Federal de Ouro Preto - UFOP

Escola de Minas

Departamento de Engenharia Civil

Ouro Preto - Minas Gerais - Brasil

ramsilveira@yahoo.com.br, ricardo@em.ufop.br

\section{Introduction}

The structure integrity under a fire condition involves the knowledge of the temperature influence in the structural behavior. Such an understanding has been achieved through increasingly sophisticated numerical models. It is known that the high temperature, which is common in a fire situation, causes changes in the physical characteristics and mechanical strength of the materials. The characteristics of both steel and concrete deteriorate during exposure to fire, and the loss of strength and stiffness increases significantly with the rising temperature. Thus, in the analysis of structures exposed to high temperatures, one important control parameter is fire exposure time. Fire resistance is defined as the ability of a material or structural element to continue carrying out, for a certain time, the functions for which it was designed, while being exposed to the action of fire. This time is called Required Fire Resistance Time (RFRT).

Through RFRT, it is possible to obtain the fictitious temperature of the ambient gases at the curve of standard fire (among other curves available in existing 
standards). By means of this temperature, it is possible to obtain the temperature of the structural element to be used in the project calculations. The temperature range of the cross section of the structural element is determined through a thermal analysis. In structural problems where fire exposure is considered, the thermal analysis basically consists of two parts: (i) determining the heat transfer by convection and radiation from the fire along the boundary of the element of interest, and (ii) determining the heat transfer by conduction in the interior of the structural elements.

Taking into consideration that the structure is exposed to fire, a consecutive resolution of the two systems of equations within each time interval can be performed.

Temporal cycle

$\Delta \mathrm{t}=1$, Max $\mathrm{N}^{0}$ of increments

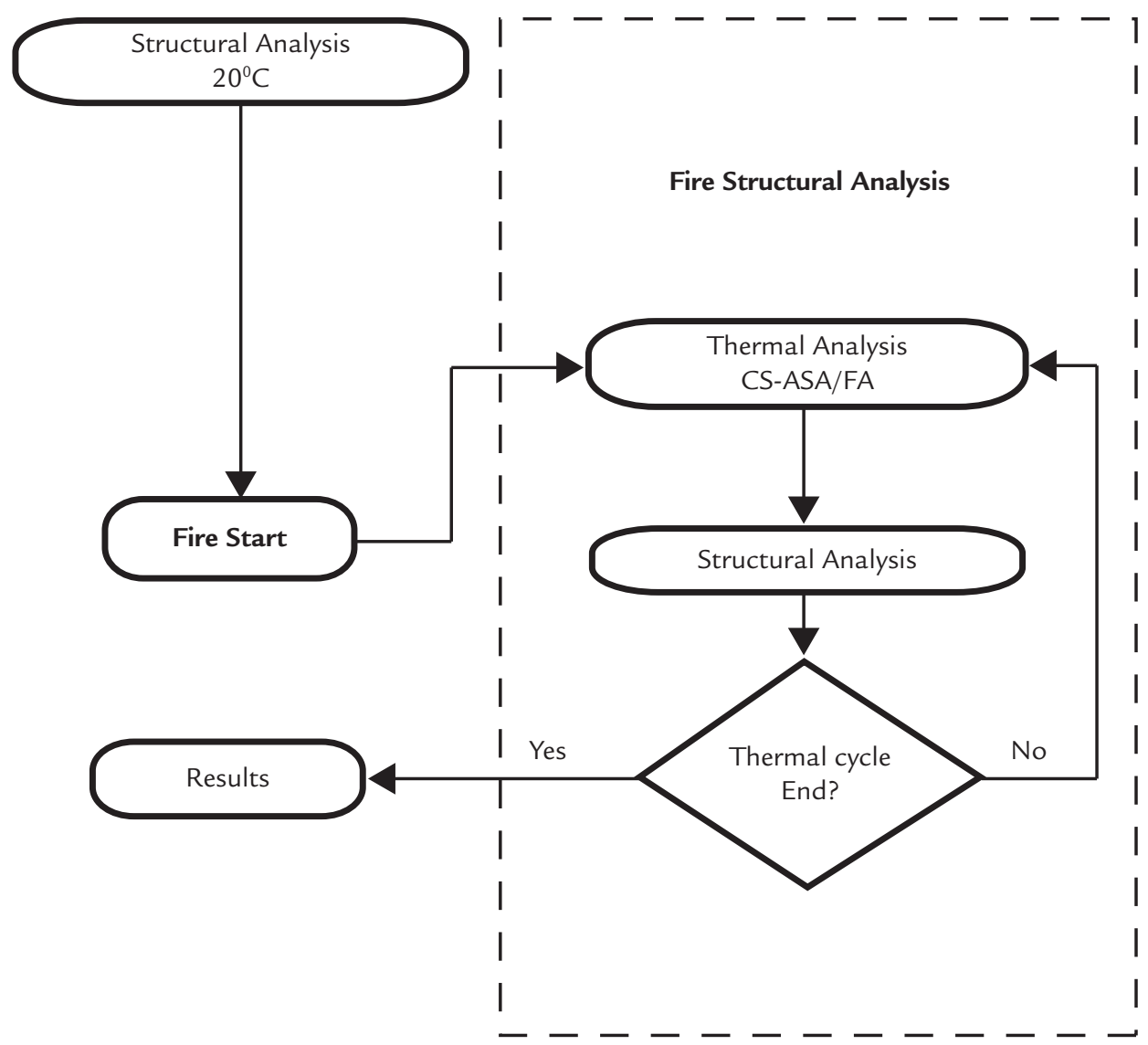

Herein, the computational module CS-ASA/FA (Computational System for Advanced Structural Analysis/Fire Analysis; Pires et al., 2015) is used to perform a thermal analysis in transient regime of steel-concrete composite cross sections of structural elements. This module was developed based on the Finite Element Method (FEM) (Cook et al., 1989) and is part of an ample computation system denominated CS-ASA (Computational System for Advanced Structural Analysis; Silva, 2009). Within the CS-ASA, the CSASA/FA is able to perform a thermal analysis of the cross section in both permanent and transient regimes, as well as a thermostructural analysis of steel structures when coupled to the module CS-ASA/FSA (Computational System for Advanced Structural Analysis/Fire Structural Analysis; Barros et al., 2016). Therefore, the objective of this study was to perform a thermal analysis of the steel-concrete composite cross sections, exploring the features of CS-ASA/FA and in the future, make it possible to thermostructurally analyze the composite structures. Within the principal characteristics of the CS-ASA/FA module, the following are worth highlighting:

- its total integration with the GID graphic pre-processor elaborated by CIMNE (2004);

- the possibility of using isoparametric triangular finite elements with 3 and 6 nodal points and isoparametric rectangles with 4 and 8 nodal points;

- the possibility of employing different strategies for the non-linear solution of thermal problems;

- its total integration with the CS-ASA/FSA module which already performs well for thermo-structural analysis
The first equation system results from the integration of the heat conduction equation (thermal analysis) and the second system corresponds to the incremental equilibrium equations (structural analysis) according to Figure 1. Therefore, the information from the thermal analysis is essential for the correct evaluation of the structure under high temperatures.
Figure 1

Solution of the thermo-structural problem.

of steel structures.

It should be noted that a large part of the research in Brazil related to the analysis of structures in fire situations has been essentially numerical, with intensive developments and advances in recent years, such as the works of: Caldas (2008); Rigobello (2011); Landesmann (2012); Pierin and Silva (2014); Pierin et al. (2015); Pires et al. (2015); Barros et al. (2016) and Barros (2016). In the international context, works by Othuman and Wang (2011), Zandi et al. (2012), Zang and Usmani (2015), and Wong (2017) can be highlighted.

The next section details the methodology used to obtain the equilibrium equation of the heat transfer problem while also explaining the nonlinear solution, which is characterized by a simple incremental or incremental-iterative scheme solution. 


\section{Equilibrium equation by FEM}

The heat conduction problem consists of solving the following par-

considering the constitutive relationship of the material (Fourier's law) and satisfying the boundary conditions. In (1), $k_{x}$ and $k_{y}$ are the thermal conductivities in the $x$ and $y$ directions, respectively, $T$ is the temperature, $Q$ is the heat generated inside the element per unit volume and time, $\rho$ is the unit material mass, $c$ is the specific heat of the material, and $t$ is the fire exposure time.

For solids, the heat transfer within the body volume (domain) occurs only by conduction. Being a solid body surrounded by a fluid, as shown in Figure 2, the convection and radiation boundary condition can be used for the solution of the solid domain problem (radiative convective bound- tial differential equation (Peréz, 2001; Halliday et al., 2009):

$$
\left(k_{x} \frac{\partial^{2} T}{\partial x^{2}}+k_{y} \frac{\partial^{2} T}{\partial y^{2}}\right)+Q=\rho c \frac{\partial T}{\partial t}
$$

ary), besides a prescribed heat flux.

Many engineering problems are governed by a valid differential equation in a domain and are subject to boundary conditions on the surface. In general, however, analytical solutions for these differential equations are known only for some simple cases. Nevertheless, the values of an unknown function (problem solution) for some predetermined points can be obtained through numerical methods. It is possible to obtain approximate solutions to differential equations using the Weighted Residual Methods (WRM). Among these methods, Galerkin stands out for its generalizability and accuracy of numerical results. This approach, together with the Finite Element Method (FEM), is applicable to a wide variety of engineering problems. FEM is a widespread numerical procedure used in the analysis of structures and continuous media. It is based on the concept of the discretization of structure and continuous media and, from there, obtaining approximate numerical solutions. Thus, FEM attempts to divide a continuous medium into subdomains, such as elements, which are interconnected through nodal points where the degrees of freedom to be determined are defined. The basic idea is to transform a complex problem into a sum of several simple problems.

Natural boundary conditions

Heat transfer by convection, radiation and heat flux prescribed on the boundary
Figure 2

Boundary conditions in a solid domain problem.

Galerkin's method is used to minimize the error when approaching the problem solution. From its weak formu- lation, and in the FEM context of considering the contribution of all elements of the mesh, it arrives at the equilibrium

$$
\mathbf{C}\left\{\frac{\partial \mathbf{T}}{\partial \mathrm{t}}\right\}+\mathbf{K}\{\mathbf{T}\}=\mathbf{R}
$$

equation governing the transient problem of heat conduction, described below in matrix form:

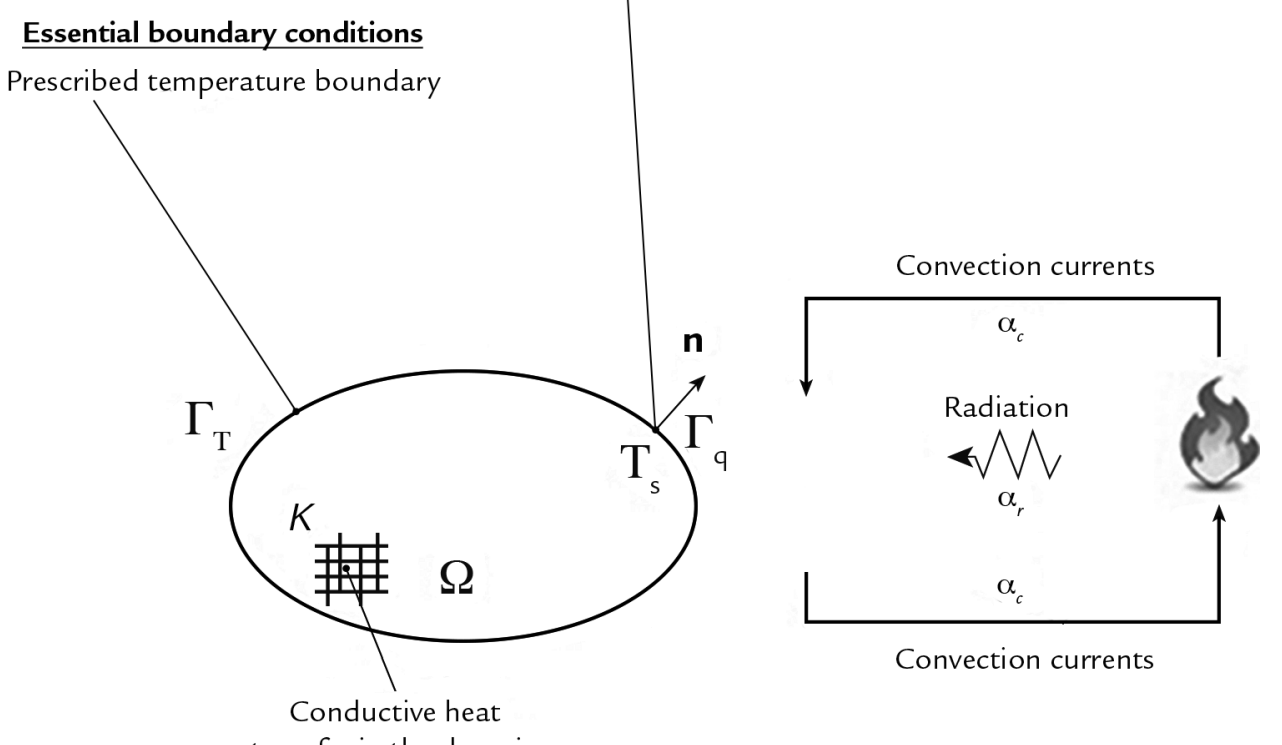


in which, $C=\int_{\Omega} \rho c N^{\top} N d \Omega$ is the capacitance matrix (thermal capacity);

$\mathbf{K}=\int_{\Omega} \mathbf{B}^{\top} \mathbf{D B} \mathrm{d} \Omega+\mathrm{h} \int_{\Gamma} \mathrm{N}^{\top} \mathbf{N} \mathrm{d} \Gamma$ is the thermal conductivity matrix;

$\mathbf{R}=\mathrm{Q} \int_{\Omega} \mathbf{N}^{\top} \mathrm{d} \Omega+\mathrm{h} \mathrm{T}_{\infty} \int_{\Gamma} \mathbf{N}^{\top} \mathrm{d} \Gamma-\mathrm{q}_{0} \int_{\Gamma} \mathbf{N}^{\top} \mathrm{d} \Gamma$ is the nodal heat flux vector; and $\mathbf{T}$ is the nodal temperatures vector meant to be determined.

The matrices $\mathbf{N}, \mathbf{B}$, and $\mathbf{D}$ in the above equations are the matrix of interpolation functions; the matrix that contains the derivatives with respect to $x$ and $y$ of the interpolation functions; and the matrix containing the thermal conductivities, $k_{x}$ and $k_{y}$. be written by a Taylor series expansion
For thermal analysis in module CS-ASA/FA, there are available: the two triangular elements T3 and T6, with 3 and 6 nodes, respectively; and two quadrilateral elements Q4 and Q8, with 4 and 8 nodes, respectively.

To solve Equation (2), this study adopts a numerical integration strategy in time based on the Finite Difference Method (FDM; Bathe, 1996; Burden and Faires, 2008). Therefore, the equilibrium equation of the transient heat conduction problem (2) can be rewritten as:

$$
\mathbf{C}_{\mathbf{n}+\theta}\left\{\frac{\partial \mathbf{T}}{\partial \mathrm{t}}\right\}_{\mathrm{n}+\theta}+\mathbf{K}\{\mathbf{T}\}_{\mathrm{n}+\theta}=\mathbf{R}_{\mathrm{n}+\theta}
$$

and, after algebraic manipulations, the equation adopted to calculate the tem-

$$
\mathbf{C}_{\mathrm{n}+\theta}\left\{\frac{T_{\mathrm{n}+1}-\mathbf{T}_{\mathrm{n}}}{\Delta \mathrm{t}}\right\}+\mathbf{K}_{\mathrm{n}+\theta}\left\{\theta T_{\mathrm{n}+1}+(1-\theta) \mathbf{T}_{\mathrm{n}}\right\}=\mathbf{R}_{\mathrm{n}+\theta}
$$

The equation above can be rearranged as follows:

$$
\left\{\mathbf{T}_{\mathrm{n}+1}\right\}=\left(\mathbf{C}_{\mathrm{n}+\theta}+\theta \Delta \mathrm{t} \mathbf{K}_{\mathrm{n}+\theta}\right)^{-1}\left[\mathbf{C}_{\mathrm{n}+\theta}-(1-\theta) \Delta \mathrm{t} \mathbf{K}_{\mathrm{n}+\theta}\right] \mathbf{T}_{\mathrm{n}}+\mathbf{R}_{\mathrm{n}+\theta}
$$

or even more compactly as:

$$
\hat{\mathbf{K}}\{\mathbf{T}\}_{\mathrm{n}+1}=\hat{\mathbf{R}}
$$

with

$$
\begin{aligned}
& \hat{\mathbf{K}}_{\mathrm{n}+\theta}=\left(\mathbf{C}_{\mathrm{n}+\theta}+\theta \Delta t \mathbf{K}_{\mathrm{n}+\theta}\right) \\
& \hat{\mathbf{R}}_{\mathrm{n}+\theta}=\left[\mathbf{C}_{\mathbf{n}+\theta}-(1-\theta) \Delta t \mathbf{K}_{\mathrm{n}+\theta}\right] \mathbf{T}_{\mathbf{n}}+\mathbf{R}_{\mathrm{n}+\theta}
\end{aligned}
$$

The temperature values in the current time step, $n+1$, are found using the temperatures calculated in the previous time step (n) and using the nodal heat flows in the current and previous time steps. Inside each time interval, the parameter $\theta$ defines the instant at which Equations (5) or (6) are satisfied. It is possible to obtain different integration schemes in time by varying the parameter $\theta$. Herein, $\theta$ is adopted as being equal to 0.9 in the analysis, in accordance with SAFIR software (Franssen, 2005). More information about integration schemes in time and a detailed problem solution of transient heat conduction can be found in Bathe (1996), Lewis et al. (2004), Rigobello (2011), Nunes (2014) and, more recently, in Barros (2016).

As can be observed, Equation (6) is strongly non-linear due to its dependency on the material's thermal properties. It is worth emphasizing that there is not a general method to resolve such a non-linear system of equations. The CS-ASA/FA module contains two implemented procedures that deal with the resolution of the system of equations described in (6): simple incremental and incremental-iterative. For the latter, the iterations can be performed through the use of the Picard algorithms, also known as a successive approximation method, and Newton-Raphson (Cook et al., 1989). The methodology described in this section is detailed in Table 1 , as well

$$
\theta_{g}=20+345 \log (8 t+1)
$$

as the solution algorithms available in CS-ASA/FA.

It should be noted here that, for a thermal analysis that describes the dynamics of fire, there exist several options of models. These models are usually represented by heating curves that are standardized and provided by current standards, or by specific curves defined for cases of nonconventional heating. In prescriptive procedures for design and laboratory testing in furnaces to determine the fire resistance of structural elements, the gas temperature is calculated using the standard fire curve (ISO 834-1). Thus, this study adopts this heating curve, which is given by:

where $\theta_{g}$ is the temperature $\left({ }^{\circ} \mathrm{C}\right)$ of the gases and $t$ is the time in minutes of fire exposure. 


\section{A. SOLUTION OF THE HEAT TRANSFER TRANSIENT PROBLEM: \\ A1. Sets input data, initial and boundary conditions \\ A2. Do: $T_{n}=T_{n+1}=T_{n+\theta}=T_{0}=20^{\circ} \mathrm{C}$ \\ B. SOLUTION PROCEDURE : Incremental simple or Incremental-iterative (Picard or Newton-Raphson) \\ C. GIVE A NEW TIME INCREMENT AND GO TO STEP B}

\section{INCREMENTAL SIMPLE}

1. INCREMENTAL PROCESS : inc $=1,2,3, \ldots$, nmáx

1a. Calculate the capacitance matrix: $\mathbf{C}_{\mathrm{n}+\theta}=\int_{\Omega} \rho c \mathbf{N}^{\top} \mathbf{N} \mathrm{d} \Omega$

1b. Calculate thermal conductivity matrix: $\mathbf{K}_{\mathrm{n}+\theta}=\int_{\Omega} \mathbf{B}^{\top} \mathbf{D B} \mathrm{d} \Omega+\mathrm{h} \int_{\Gamma} \mathbf{N}^{\top} \mathbf{N} \mathrm{d} \Gamma$

1c. Calculates the heat flux vector: $\mathbf{R}_{\mathrm{n}+\theta}=\mathrm{Q} \int_{\Omega} \mathrm{N}^{\top} \mathrm{d} \Omega+\mathrm{h} \mathrm{T}_{\infty} \int_{\Gamma} \mathrm{N}^{\top} \mathrm{d} \Gamma-q_{0} \int_{\Gamma} \mathrm{N}^{\top} \mathrm{d} \Gamma$

1d. Get: $\hat{\mathbf{K}}_{\mathrm{n}+\theta}=\left(\mathbf{C}_{\mathrm{n}+\theta}+\theta \Delta \mathrm{t} \mathbf{K}_{\mathrm{n}+\theta}\right)$

1e. Get: $\hat{\mathbf{R}}_{\mathrm{n}+\theta}=\left[\mathbf{C}_{\mathrm{n}+\theta}-(1-\theta) \Delta \mathrm{t} \mathbf{K}_{\mathrm{n}+\theta}\right] \mathbf{T}_{\mathbf{n}}+\mathbf{R}_{\mathrm{n}+\theta}$

1f. Solve the system of equations: $\{\mathbf{T}\}_{\mathrm{n}+1}=\hat{\mathbf{K}}_{\mathrm{n}+\theta}^{-1} \hat{\mathbf{R}}_{\mathrm{n}+\theta}$

INCREMENTAL -ITERATIVE (PICARD)

1. INCREMENTAL PROCESS : $i n c=1,2, \ldots, \operatorname{nmax}$

2. ITERATIVE PROCESS (PICARD) : $k=1,2, \ldots, n \max$

2a. Do: $\hat{\mathbf{R}}_{\mathbf{n}+\theta}=\mathbf{T}_{\mathbf{n}+\theta}^{1}=\mathbf{T}_{\mathrm{n}+\theta}^{2}=0.0$

2b. Calculate the capacitance matrix:

$\mathbf{C}_{n+\theta}=\int_{\Omega} \rho \mathrm{d} \mathbf{N}^{\top} \mathbf{N} \mathrm{d} \Omega$

2c. Calculate thermal conductivity matrix:

$\mathbf{K}_{\mathrm{n}+\theta}=\int_{\Omega} \mathbf{B}^{\top} \mathbf{D B} \mathrm{d} \Omega+\mathrm{h} \int_{\Gamma} \mathbf{N}^{\top} \mathbf{N} \mathrm{d} \Gamma$

2d. Calculate the heat flux vector:

$\mathbf{R}_{\mathrm{n}+\theta}=\mathrm{Q} \int_{\Omega} \mathbf{N}^{\top} \mathrm{d} \Omega+\mathrm{h} \mathrm{T}_{\infty} \int_{\Gamma} \mathbf{N}^{\top} \mathrm{d} \Gamma-\mathrm{q}_{0} \int_{\Gamma} \mathbf{N}^{\top} \mathrm{d}$

2e. Get: $\hat{\mathbf{K}}_{\mathrm{n}+\theta}=\left(\mathbf{C}_{\mathrm{n}+\theta}+\theta \Delta \mathrm{t} \mathbf{K}_{\mathrm{n}+\theta}\right)$

2f. Get: $\hat{\mathbf{R}}_{\mathrm{n}+\theta}=\left[\mathbf{C}_{\mathrm{n}+\theta^{-}}(1-\theta) \Delta \mathrm{t} \mathbf{K}_{\mathrm{n}+\theta}\right] \mathbf{T}_{\mathrm{n}}+\mathbf{R}_{\mathrm{n}+\theta}$

2g. Determines the 1 st approximation:

$\mathbf{T}_{\mathrm{n}+\theta}^{1}=\hat{\mathbf{K}}_{\mathrm{n}+\theta}^{-1} \hat{\mathbf{R}}_{\mathrm{n}+\theta}$

2h. Determines the 2 nd approximation:

$\mathbf{T}_{\mathrm{n}+\theta}^{2}=\mathbf{T}_{0}+2\left(\mathbf{T}_{\mathrm{n}+\theta}-\mathbf{T}_{0}\right)$

2i. Checks for convergence: $\frac{\left\|\mathbf{T}_{\mathrm{n}+\theta}^{1}-\mathbf{T}_{\mathrm{n}+\theta}^{2}\right\|}{\left\|\mathbf{T}_{\mathrm{n}+\theta}^{1}\right\|}<$ tolerance

YES :

Calculate the vector $\mathbf{T}_{\mathrm{n}+\theta}=\mathbf{T}_{\mathrm{n}+\theta}^{1}+0.5\left(\mathbf{T}_{\mathrm{n}+\theta}^{1}-\mathbf{T}_{0}\right)$

Update vector $\quad \mathbf{T}_{0}=\mathbf{T}_{\mathrm{n}+\theta}^{1}$ and go to item $\mathrm{C}$

NO:

$\overline{\text { If } k}<$ nmax, calculate

$\mathbf{T}_{\mathrm{n}+\theta}=0.5\left(\mathbf{T}_{\mathrm{n}+\theta}+0.5\left(\mathbf{T}_{\mathrm{n}+\theta}^{1}+\mathbf{T}_{0}\right)\right)$ and returns to

step2

If $k=n \max$, stop and try another strategy
INCREMENTAL -ITERATIVE (NEWTON-RAPHSON)

1. INCREMENTAL PROCESS : $i n c=1,2, \ldots, n \max$

1a. Calculate the capacitance matrix:

$\mathbf{C}_{\mathrm{n}+\theta}=\int_{\Omega} \rho c \mathbf{N}^{\top} \mathbf{N} \mathrm{d} \Omega$

1b. Calculate thermal conductivity matrix:

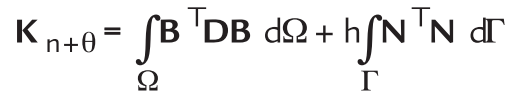

1c. Calculate the heat flux vector:

$\mathbf{R}_{\mathrm{n}+\theta}=\mathrm{Q} \int_{\Omega} \mathbf{N}^{\top} \mathrm{d} \Omega+\mathrm{hT}_{\infty} \int_{\Gamma} \mathbf{N}^{\top} \mathrm{d} \Gamma-\mathrm{q}_{0} \int_{\Gamma} \mathbf{N}^{\top} \mathrm{d} \Gamma$

1d. Get: $\hat{\mathbf{K}}_{\mathrm{n}+\theta}=\left(\mathbf{C}_{\mathrm{n}+\theta}+\theta \Delta \mathrm{t} \mathbf{K}_{\mathrm{n}+\theta}\right)$

1e. Get: $\hat{\mathbf{R}}_{\mathrm{n}+\theta}=\left[\mathbf{C}_{\mathrm{n}+\theta}-(1-\theta) \Delta \mathrm{t} \mathbf{K}_{\mathrm{n}+\theta}\right] \mathbf{T}_{\mathrm{n}}+\mathbf{R}_{\mathrm{n}+\theta}$

1f. Solve the system of equations: $\{\mathbf{T}\}_{n+1}=\hat{\mathbf{K}}_{n+\theta}^{-1} \hat{\mathbf{R}}_{\mathrm{n}+\theta}$

2. ITERATIVE PROCESS (N-R): $k=1,2, \ldots, n \max$

2a. Update $\hat{\mathbf{K}}_{n+\theta}$ and $\hat{\mathbf{R}}_{n+\theta}$ for $\mathbf{T}_{n+1}$

2b. Solve the system defined in $1 \mathrm{f}$ to obtain $\mathbf{T}_{\mathrm{n}+1}^{k}$

2c. Calculates the unbalance vector:

$\mathbf{g}=\hat{\mathbf{R}}_{\mathrm{n}+\theta}-\hat{\mathbf{K}}_{\mathrm{n}+\theta}\{\mathbf{T}\}_{\mathrm{n}+1}$

2d. Get the correction of the nodal temperatures:

$\delta \mathbf{T}^{k}=\left[\hat{\mathbf{K}}_{\mathrm{n}+\theta}\right]^{-1} \mathbf{g}\left(\mathbf{T}^{(k-1)}\right)$

2e. Updates nodal temperatures:

$\mathbf{T}_{\mathrm{n}+1}^{k}=\mathbf{T}_{\mathrm{n}+1}^{(k-1)}+\delta \mathbf{T}_{\mathrm{n}+1}^{k}$

2f. Checks for convergence: $\frac{\left\|\mathbf{T}_{\mathrm{n}+1}^{k}-\mathbf{T}_{\mathrm{n}+1}^{(k-1)}\right\|}{\left\|\mathbf{T}_{\mathrm{n}+1}^{k}\right\|}<$ tolerance

YES : Stop and proceed to item $C$

NO: If $k<n$ max, returns to step 2

If $k=n \max$, stop and try another strategy 
The other heating curves, although they have been implemented in the

\section{Numerical examples}

This section aims to determine, by transient thermal analysis, the structural behavior of composite cross sections subjected to high temperatures, using the CS-ASA/FA (Pires et al., 2015). As already mentioned, this module is part of the CS-ASA program (Silva, 2009) and was developed for the analysis of structures exposed to fire. Therefore, it is indispensable that the thermal analysis be performed in a correct manner so as not to compromise

\subsection{Concrete-filled steel tubular section}

The first example, shown in Figure 3a, concerns a rectangular, steel concrete-filled tubular section. Yang et al. (2013) pointed out that, in recent decades, researchers have studied in depth the behavior of this cross section's structural elements subjected to uniform fire. Where knowledge is limited, however, is on the performance of the structural components when exposed to fire on three sides, a common real-world scenario. Hence, these authors analyzed such an example, experimentally, using a ceramic fiber blanket to simulate the side
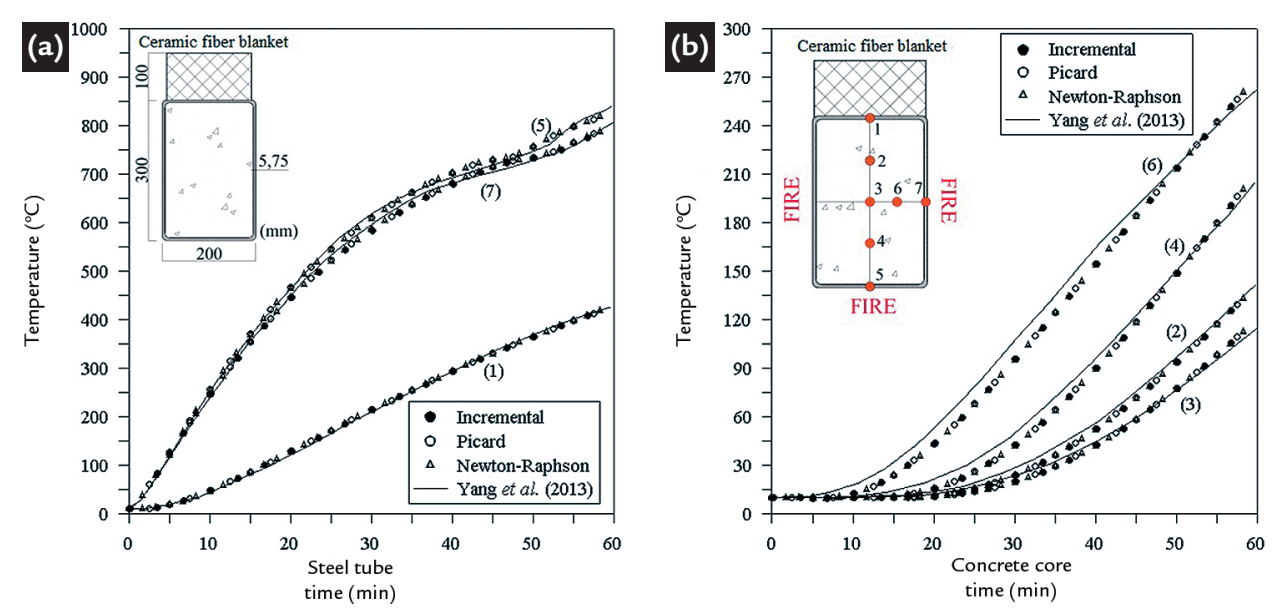

CS-ASA/FA, are not addressed in this study. However, more information on

them can be obtained from Franssen et al. (2009), Bailey (2011) and Barros (2016).

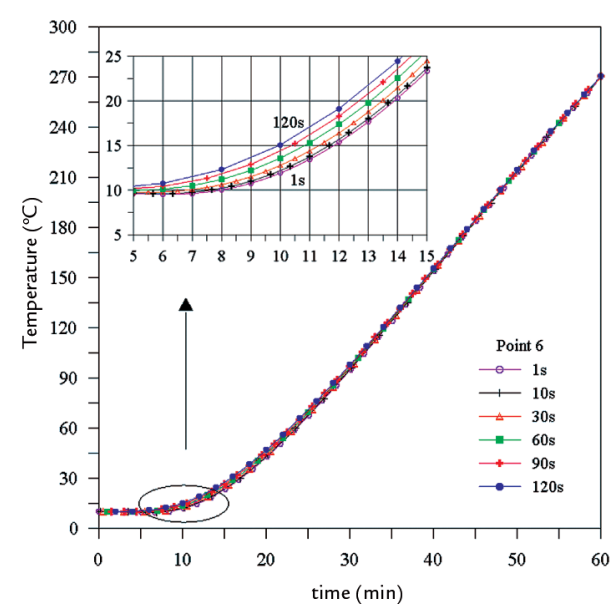

the response of the thermo-structural analysis. The CS-ASA/FA module was used with success by Barros (2016) in the first step of the thermo-structural analysis of steel structures. Herein, two steel-concrete composite cross sections having different geometric and physical characteristics are analyzed to evaluate the capacity of CS-ASA/FA to supply the necessary information from the thermal analysis for the composite structures. Besides this, results

not exposed to fire.

Figure 3 shows the temperature distribution within the cross section being studied: in (a) the points on the steel profile, and (b) the points in the concrete region. For the discretization of the cross section, the study adopted a mesh structured with 308 quadrilateral finite elements, linear. A time increment, $\Delta \mathrm{t}$, of $10 \mathrm{~s}$ was used. It can be seen that the obtained responses in this study show good agreement with the experimental results.

To verify the influence of the time

Figure 3

Temperature versus time curves: concrete-filled steel tubular section.

Figure 4

Variation of the time increment to point 6.

are obtained for two types of solution processes: simple incremental and incrementaliterative (Picard or Newton-Raphson). The objective is to demonstrate the influence of these processes on the response of the problem. The thermal properties of steel are those given by EN 1993-1-2: 2005 and of concrete are those given by EN 1992-1-2: 2004, considered to be varying with the temperature. The adopted parameters are highlighted in each example below.

increment, $\Delta t$, in obtaining the temperature distribution in the section, the study adopted point 6 in the concrete region (Figure $3 \mathrm{~b}$ ) and $\Delta \mathrm{t}$ was varied by the following values: 1 s, 10 s, 30 s, 60 s, 90 s, and 120s. The results are shown in Figure 4. See that with a larger increment of time, the temperature tends to be higher in the first few minutes of exposure to fire (between 5 to $20 \mathrm{~min}$ ). A maximum difference was observed of about $4^{\circ} \mathrm{C}$ between curves where $\Delta \mathrm{t}$ was equal to $1 \mathrm{~s}$ and $120 \mathrm{~s}$. As the fire exposure time increases, the curves practically coincide.

\section{concrete-filled steel tubular section.}

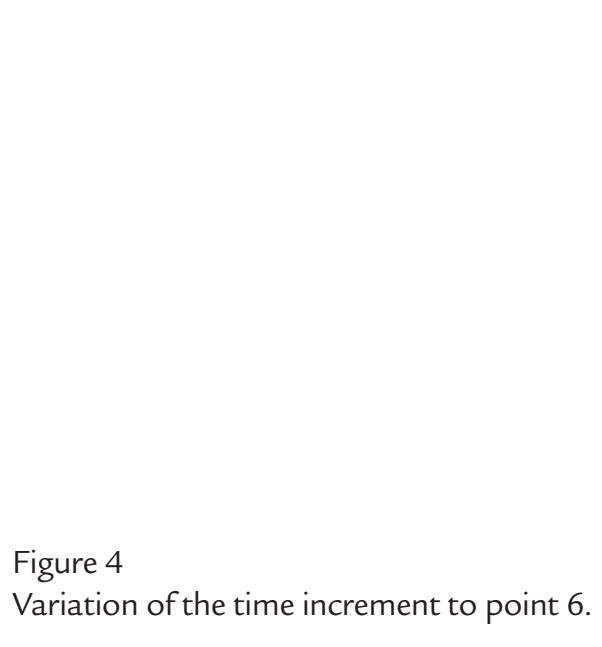




\subsection{Steel-concrete composite beam section}

The other section chosen to evaluate its behavior under the action of fire was the cross section of a composite beam of steel and concrete, illustrated in Figure 5a.

The composite beam was made by the IPE 500 profile. It is part of a sevenstory structure studied by Behnam and Rezvani (2014). Using SAFIR software, these authors investigated the structure being subjected to the action of fire spreading (Franssen, 2005). The study also considered the uniform action of fire represented by the curve described by Equation (7). The results presented by the

Figure 5

Distribution of temperature inside beam.

Figure 6

Variation of the

cross-section's finite element mesh.

\section{Final remarks}

In numerical contexts, the analysis of structural elements at high temperatures is made possible by two fundamental phases: thermal analysis and structural analysis, which are interconnected. It is important to consider how the inelastic behavior of the material is affected by temperature as well as to consider the second-order effects that arise due to changes in geometry. After all, it is known that the structural elements bearing capacity is significantly reduced as temperatures rise. In addition to changing the characteristics of the cross authors, considering the ISO-834 curve, are used for comparison.

Figure $5 \mathrm{~b}$ shows the temperatureversus-time curve for five points of the cross-section. It is noteworthy that for the discretization of the section this study used a mesh structured with 530 quadrilateral finite elements and 4 triangular finite elements, both linear, which is shown in Figure 6a. Again, you can see there is good agreement between the results obtained in this study and those provided by Behnam and Rezvani (2014).

In obtaining the temperature distri- bution in the section, point 4 was chosen to check the influence of discretization of the finite element mesh. The adopted meshes are illustrated in Figure 6a, where the number of finite elements used in each is highlighted. Two meshes were adopted (MESH 1 and 2) that were less refined than the mesh initially adopted for the study of the section (MESH 3). The results are shown in Figure 6b, where it can be clearly seen that the more refined the mesh produced, the better the result; that is, the values converge more with those found in literature. (a)

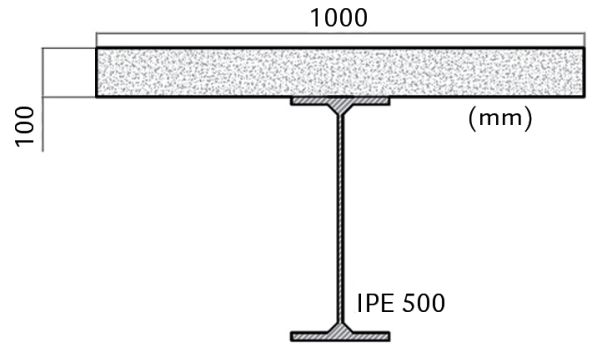

Beam`s cross-section and slab

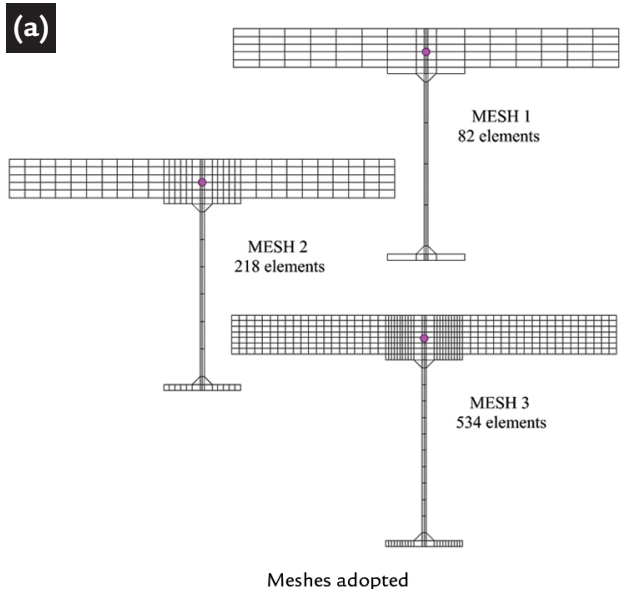

(b)

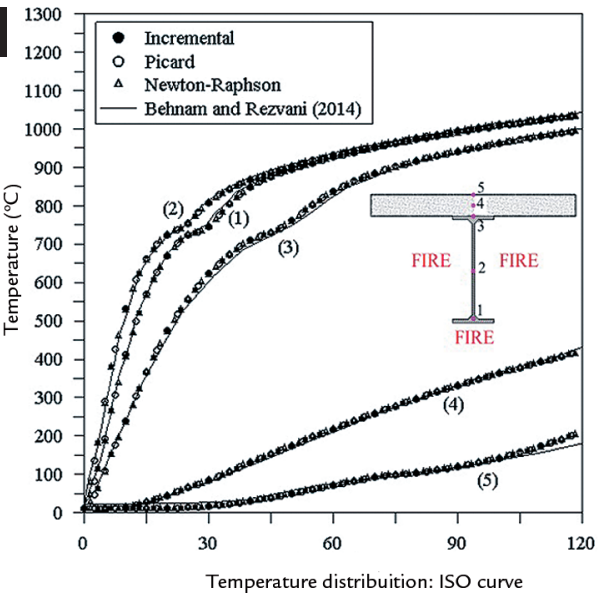

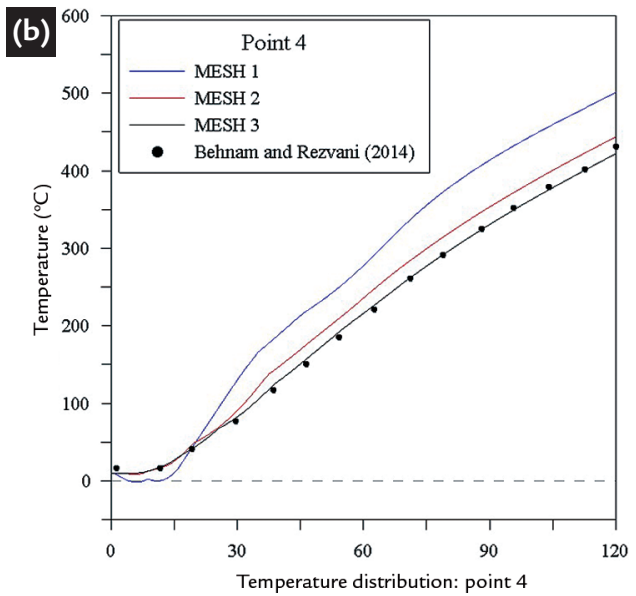

section, a temperature increase also causes the appearance of thermal strains in the stretching behavior of materials. Thus, the information from the thermal analysis is key to achieving, in a satisfactory way, the thermo-structural behavior.

This article presents the thermal analysis of cross sections of structural elements commonly used in construction. The results were compared with the experimental and numerical solutions found in literature.

From the examples analyzed in the

previous section, we can conclude that the CS-ASA/FA computation module can satisfactorily simulate the effect of high temperatures on the cross sections of structural elements. These results have agreed with those found in literature. Both experimental (Yang et al., 2013) and numerical (Behnam and Rezvani, 2014) results found in literature were used for comparison.

In addition, it was possible to verify the influence of two solution procedures: simple incremental and incremental- 
iterative (Picard and Newton-Raphson), as well as the length of the incremental time and the mesh of the finite elements; all of which influence temperature distribution. It has also been observed that the two solution procedures are efficient in obtaining the thermal response of the two sections and almost no difference was verified in the response between them. The simple incremental procedure is more efficient regarding the processing time in function of the solution algorithm shown in Table 1, where the volume of operations needed to be performed is less. However, a deeper study involving more samples and analysis situations is necessary to define a better option for the solution in this case. Regarding the time incremental variation adopted in

\section{Acknowledgments}

The authors are grateful for the financial support received by CAPES, CNPq, this analysis, an insignificant influence was encountered, or in other words, there occurred a maximum difference of $4^{\circ} \mathrm{C}$ between the values of $1 \mathrm{~s}$ and $120 \mathrm{~s}$. This difference between the curves (temperature versus time) may be related to the standard fire curve, Equation (7), since it varies logarithmically. Adopting time increment values equal to 1 s and 120 s, the gas temperature is equal to $38.75^{\circ} \mathrm{C}$ and $444.50^{\circ} \mathrm{C}$, respectively, at the end of the first time increment. However, there can be seen in Figure 4 a small variation of structural element temperature (cross section), about $4^{\circ} \mathrm{C}$. This small influence of the time increment allows larger values to be used without compromised response, since smaller incremental values lead to a higher processing time. A greater sensibil- ity was observed in relation to the finite element mesh discretization. Depending on the cross section, too coarse a mesh would not accurately represent the physical problem (MESH 1), being necessary a certain refinement for better results, as verified in the second example presented. It is worth mentioning that more detailed studies about the finite element mesh discretization and the time increment were presented in Barros et al. (2016), for steel cross sections, who also used the CS-ASA/FA computational module.

Finally, we can affirm the CS-ASA/ FA module is also efficient in the thermal analysis of steel-concrete composite cross sections, being able to supply data for a future thermo-structural analysis of composite structures exposed to fire.
FAPEMIG and UFOP. They also thank professors John White and Harriet Reis by text review.

\section{References}

BAILEY, C. G. One Stop Shop in Structural Fire Engineering by Manchester University. [online] Disponível: http://www.mace.manchester.ac.uk/project/research/ structures/strucfire/, 2011.

BARROS, R.C., PIRES, D., LEMES, I.J.M., ROCHA, P.A.S., SILVEIRA, R.A.M. Análise termomecânica de estruturas de aço via acoplamento MCD/MRPR. In: Ibero-Latin American Congress on Computational Methods in Engineering, 37. Brasília, DF, Brasil, v.2, p. 237-253, 2016.

BARROS, R.C. Avaliação numérica avançada do desempenho de estruturas de aço sob temperaturas elevadas. Ouro Preto: Programa de Pós-Graduação em Engenharia Civil, Deciv/EM/UFOP, 2016. (Dissertação de Mestrado).

BATHE, K.J. Finite element procedures. New Jersey: Prentice-Hall, 1996. 1037 p.

BEHNAM, B., REZVANI, F. H. Structural evaluation of tall steel moment-resisting structures in simulated horizontally traveling postearthquake fire. Journal of Performance of Constructed Facilities, 04014207(12), 2014.

BURDEN, R. L., FAIRES, J. D. Análise numérica ( $8^{\mathrm{a}}$ ed.). CENGAGE Learning, 2008. $736 \mathrm{p}$.

CALDAS, R. B. Análise numérica de estruturas de aço, concreto e mistas em Situação de Incêndio. Belo Horizonte: Programa de Pós-Graduação em Engenharia de Estruturas, EE/UFMG, 2008. (Tese de Doutorado).

CIMNE. GID Pré/pos Processador Gráfico - Versão 7.2. Centro Internacional de Métodos Numéricos em Engenharia. Barcelona, 2004.

COOK, R., MALKUS, D., PLESHA, M. Concepts and applications of finite element analysis. (3rd ed.). New York: John Willey \& Sons, 1989.

EN 1992-1-2. Eurocode 2 - Design of concrete structures. Part 1-2: General rules, structural fire designing. European Committee for Standardization - CEN, Brussels, 2004.

EN 1993-1-2. Eurocode 3 - Design of steel structures. Part 1-2: General rules, structural fire desing. European Committee for Standardization - CEN, Brussels, 2005.

FRANSSEN, J. M., KODUR, V., ZAHARIA, R. Designing steel structures for fire safety. CRC Press, 2009.

FRANSSEN, J. M. SAFIR - A thermal/structural program modelling structures under fire. Engineering Journal AISC, v.42, n.3, p. 143-158, 2005.

HALLIDAY, D., RESNICK, R., WALKER, J. Fundamentos de Física 2. (8a ed.). São Paulo, Livros Técnicos e Científicos Editora, 2009. 295 p. 
ISO 834-1. Fire resistance tests - Elements of buildings construction, Part 1: General requirements. ISO - International Organization for Standardization, Geneva, 1999.

LANDESMANN, A. Refined plastic-hinge model for analysis of steel-concrete structures exposed to fire. Journal of Constructional Steel Research, 71, p. 202-209, 2012.

LEWIS, R. W., NITHIARASU, P., SEETHARAMU, K. N. Fundamentals of the finite element method for heat and fluid flow. Chichester: John Wiley \& Sons, 2004.

NUNES, N. E. M. Código computacional para análise térmica tridimensional de Estruturas em situação de incêndio. São Carlos: Programa de Pós-Graduação em Engenharia de Estruturas - Escola de Engenharia de São Carlos da Universidade de São Paulo, 2014. 152 f. (Dissertação de Mestrado).

OTHUMAN, M. A., WANG, Y. C. Elevated-temperature thermal properties of lightweight foamed concrete. Construction and Building Materials, 25, p. 705-716, 2011.

PÉREZ, J. P. Thermodynamique. Fondements et applications. Paris, Masson. (3rd ed). 2001. 584 p.

PIERIN, I., SILVA, V. P., LA ROVERE, H. L. Análise térmica de estruturas bidimensionais em situação de incêndio. Revista IBRACON de Estruturas e Materiais, 8, p. 25-48, 2015.

PIERIN, I., SILVA, V. P. Análise térmica de estruturas bidimensionais em situação de incêndio por meio do método dos elementos finitos. Jornadas Sul Americanas de Engenharia Estrutural, 2014.

PIRES, D., BARROS, R.C., LEMES, I.J.M., SILVEIRA R.A.M., ROCHA, P.A.S. Análise térmica de seções transversais via método dos elementos finitos. In: CILAMCE, 36. Anais... Rio de Janeiro, RJ, Brasil, v. 1, p. 1-19, 2015.

RIGOBELLO, R. Desenvolvimento e aplicação de código computacional para análise de estruturas de aço aporticadas em situação de incêndio. São Carlos: Programa de Pós-Graduação em Engenharia de Estruturas - Escola de Engenharia de São Carlos da Universidade de São Paulo, 2011. 272 f. (Tese de Doutorado).

SILVA, A.R.D. Sistema computacional para a análise avançada estática e dinâmica de estruturas metálicas. Ouro Preto: Programa de Pós-graduação em Engenharia Civil, DECIV/Escola de Minas/UFOP, 2009. 322 f. (Tese de Doutorado).

WONG, M. B. Temperature analysis of partially heated steel members in fire. Journal of Constructional Steel Research, 128, p. 1-6, 2017.

YANG, H., LIU, F., GARDNER, L. Performance of concrete-filled RHS columns exposed to fire on 3 sides. Engineering Structures, 56, p. 1986-204, 2013.

ZANDI, Y., BURNAZ, O., DURMUŞ, A. Determining the temperature distributions of fire exposed reinforced concrete cross-sections with different methods. Research Journal of Environmental and Earth Sciences, v.4, n.8, p. 782-788, 2012.

ZANG, C., USMANI, A. Heat transfer principles in thermal calculation of structures in fire. Fire Safety Journal, 78, p. 85-95, 2015.

Received: 1 November 2016 - Accepted: 3 June 2017. 